\title{
BMJ Global Health Global health, global surgery and mass casualties: II. Mass casualty centre resources, equipment and implementation
}

\author{
Sergio Aguilera, ${ }^{1}$ Leonidas Quintana, ${ }^{2,3}$ Tariq Khan, ${ }^{3,4}$ Roxanna Garcia, ${ }^{5}$ \\ Haitham Shoman (D) , ${ }^{6}$ Luke Caddell, ${ }^{6,7}$ Rifat Latifi, ${ }^{8,9}$ Kee B Park, ${ }^{6}$ \\ Patricia Garcia, ${ }^{10}$ Robert Dempsey, ${ }^{11,12}$ Jeffrey V Rosenfeld, ${ }^{13,14}$ Corey Scurlock, ${ }^{15}$ \\ Nigel Crisp, ${ }^{16,17}$ Lubna Samad, ${ }^{18,19}$ Montray Smith, ${ }^{20}$ Laura Lippa, ${ }^{21}$ \\ Rashid Jooma, ${ }^{22,23}$ Russell J Andrews (D) ${ }^{3,24}$
}

\begin{abstract}
To cite: Aguilera S, Quintana L, Khan T, et al. Global health, global surgery and mass casualties: II. Mass casualty centre resources, equipment and implementation. BMJ Global Health 2020;5:e001945. doi:10.1136/ bmjgh-2019-001945
\end{abstract}

Handling editor Seye Abimbola

Received 27 August 2019 Revised 28 November 2019 Accepted 30 November 2019

\section{SLinked}

- http://dx.doi.org/10.1136/ bmjgh-2019-001943

Check for updates

(C) Author(s) (or their employer(s)) 2020. Re-use permitted under CC BY-NC. No commercial re-use. See rights and permissions. Published by BMJ.

For numbered affiliations see end of article.

Correspondence to Dr Russell J Andrews; rja@russelljandrews.org

\section{ABSTRACT}

Trauma/stroke centres optimise acute 24/7/365 surgical/ critical care in high-income countries (HICs). Concepts from low-income and middle-income countries (LMICs) offer additional cost-effective healthcare strategies for limited-resource settings when combined with the trauma/ stroke centre concept. Mass casualty centres (MCCs) integrate resources for both routine and emergency care-from prevention to acute care to rehabilitation. Integration of the various healthcare systems governmental, non-governmental and military-is key to avoid both duplication and gaps. With input from LMIC and HIC personnel of various backgrounds - trauma and subspecialty surgery, nursing, information technology and telemedicine, and healthcare administration-creative solutions to the challenges of expanding care (both daily and disaster) are developed. MCCs are evolving initially in Chile and Pakistan. Technologies for cost-effective healthcare in LMICs include smartphone apps (enhance prehospital care) to electronic data collection and analysis (quality improvement) to telemedicine and drones/robots (support of remote regions and resource optimisation during both daily care and disasters) to resilient, mobile medical/surgical facilities (eg, battery-operated CT scanners). The co-ordination of personnel (within LMICs, and between LMICs and HICS) and the integration of cost-effective advanced technology are features of MCCs. Providing quality, cost-effective care 24/7/365 to the 5 billion who lack it presently makes MCCs an appealing means to achieve the healthcare-related United Nations Sustainable Development Goals for 2030.

\section{INTRODUCTION}

Progress toward the United Nations (UN) healthcare-related Sustainable Development Goals (SDGs) for 2030 requires addressing acute conditions (injury, complicated childbirth, acute abdomen) and noncommunicable diseases (neoplasia, cardiovascular events, musculoskeletal disorders). ${ }^{1}$ Progress towards those SDGs also requires
Summary box

Low-income and middle-income country (LMIC) healthcare is frequently resource-poor (government sector), costly beyond the means of the populace (private sector) and fragmented (civilian vs military vs private sector).

- Cost-effective technologies (smartphones, digita data collection and analysis, cost-effective and resilient medical devices) can greatly enhance LMIC healthcare delivery.

- National Surgical, Obstetric and Anaesthesia Plans (NSOAPs) are providing a structure for LMICs to achieve the healthcare-related United Nations Sustainable Development Goals for 2030.

- Adapting the trauma/stroke centre model (from prevention to prehospital care to acute and critical care to rehabilitation) for an LMIC- - together with collaboration between LMIC and HIC medical personnelreduces morbidity and mortality during both daily and mass casualty disaster situations.

- A global Mass Casualty Centre network provides the co-ordination, integration and standardisation in healthcare delivery, personnel training, data collection and research that are essential to achieve both NSOAPs and United Nations Sustainable Development Goals for 2030.

addressing the morbidity/mortality resulting from the healthcare infrastructure failure and delayed response that accompany mass casualty disasters-whether natural (earthquakes, hurricanes, floods) or man-made (building collapse, transportation accidents, terrorist events). These issues are particularly prominent in low-income and middle-income countries (LMICs) - where the majority of the 5 billion people who lack basic surgical care reside.

Over half the deaths and roughly $40 \%$ of the disease burden in LMICs are the result of conditions treatable with prehospital and 
emergency care. ${ }^{2}$ In preparation for the 72nd World Health Assembly (Geneva May 2019), the WHO DirectorGeneral published a report affirming the importance of the emergency care system for global health (for both daily healthcare and mass casualty events) ${ }^{3}$ :

The emergency care system... extends from care at the scene through transport and emergency unit care, and it ensures access to early operative and critical care when needed... Implementing community-based education and first-aid training, certification for prehospital providers and 24 hours availability of emergency unit services at firstlevel hospitals save lives and maximize the effectiveness of later interventions. Well-organized emergency care is therefore a key mechanism for achieving a range of SDG targets, including those on universal health coverage, road safety, maternal and child health, noncommunicable diseases, infectious diseases, disasters and violence... Besides meeting the everyday health needs of the population, a well-organized, prepared and resilient emergency care system has the capacity to maintain essential acute care delivery throughout a mass event... Everyday emergency care systems are an essential substrate for effective emergency response. ${ }^{3}$

Mass casualty centres (MCCs) address both acute healthcare conditions and healthcare infrastructure failure in disasters (and 'routine' power outages) ${ }^{4}$ by providing resilient and mobile 24/7/365 healthcare that is an integral part of the ongoing healthcare system. The rationale for MCCs - an extension of the trauma/stroke centre model established decades ago in high-income countries (HICs) - is presented in the companion article (Khan T, Quintana L, Aguilera S, et al. Global health, global surgery and mass casualties: I. Rationale for integrated mass casualty centres in BMJ Global Health).

Progress towards universal health coverage requires addressing both the full continuum of care and the breadth of resources necessary to provide that care. The MCC concept incorporates prevention, prehospital care, acute and critical care, and rehabilitation. The breadth of resources includes the personnel (physicians, dentists, nurses, allied health professionals, administrators, biomedical support staff, information technologists) and the equipment (from self-contained mobile operating rooms and critical care units to data collection and analysis platforms to telemedicine resources to robots and drones) required to impact healthcare significantly. The UN Office for Disaster Risk Reduction (DRR) has

Table 1 Estimated deaths from cyclones/typhoons in South and Southeast Asia

\begin{tabular}{|c|c|c|c|c|}
\hline Name & Country & Date & $\begin{array}{l}\text { Maximum } \\
\text { wind speed } \\
(\mathrm{km} / \mathrm{h})\end{array}$ & $\begin{array}{l}\text { Estimated } \\
\text { deaths }\end{array}$ \\
\hline Nargis & Myanmar & Apr 2008 & 215 & $\sim 140000$ \\
\hline Phailin & India & Oct 2013 & 260 & $<50$ \\
\hline Haiyan & Philippines & Nov 2013 & 315 & $\sim 7000$ \\
\hline \multicolumn{5}{|c|}{$(\text { references) })^{23} 48-50$} \\
\hline
\end{tabular}

published a guide for implementing the Sendai Framework for DRR, including a checklist that in essence describes the MCC concept. ${ }^{5}$

This article presents aspects of the personnel and equipment of the MCC concept, and requirements for implementation. Progress on the initial MCC models in Peshawar (Pakistan) and Iquique (Chile) is described. Although not exhaustive, sufficient detail is presented to demonstrate that MCCs are a practical and cost-effective strategy towards the healthcare-related SDGs for 2030.

\section{PERSONNEL AND TRAINING}

Half of the global healthcare workforce consists of nurses and midwives (hereafter considered jointly as 'nurses'), and they are involved in $90 \%$ of contacts between patients and health professionals. ${ }^{6}$

\section{Nurses}

Nurses are crucial to expanding high-quality healthcare across the continuum from prevention to follow-up care. ${ }^{3}$ They are ubiquitous in all aspects of healthcare-from prevention and patient education to acute hospital care to rehabilitation and home care to palliative and hospice care. Nurses provide direct care and are also the mainstay of patient education-roles from teacher to treatment provider to social worker ${ }^{7}$ :

... nurses have especially crucial roles to play in health promotion and health literacy... nurses are uniquely placed to act as effective practitioners, health coaches, spokespersons, and knowledge suppliers for patients and families throughout their life course. ${ }^{7}$

Nurses are critical to disaster response teams, such as the WHO Emergency Medical Team (WHO EMT), the Australian Medical Assistance Team (AUSMAT) and the Disaster Medical Assistance Teams (DMATs) of the National Disaster Medical System in the USA. ${ }^{8-11}$ DMATs nurses provide care for state and local healthcare systems during a disaster, staff both fixed and temporary medical sites, are self-sufficient for at least 72 hours and can provide support for up to 2 weeks. ${ }^{11}$

\section{Training for mass casualty disasters}

The programmes noted above-WHO EMT and AUSMAT (introduced in the companion article)-are examples of detailed programmes to train healthcare professionals for mass casualty disasters. WHO EMT has a 54-page publication "Minimum Technical Standards and Recommendations for Rehabilitation for Emergency Medical Teams" "12; AUSMAT and its partner National Critical Care and Trauma Research Centre in Darwin include firefighters among their personnel, and courses such as "Emergency Management of Severe Burns" in their training programmes. ${ }^{8}$ A broad range of personnel is involved in mass casualty response.

\section{Twinning or dyads}

Twinning (or dyads) is one technique for ongoing training between HIC and LMIC healthcare personnel. ${ }^{13-16}$ The 


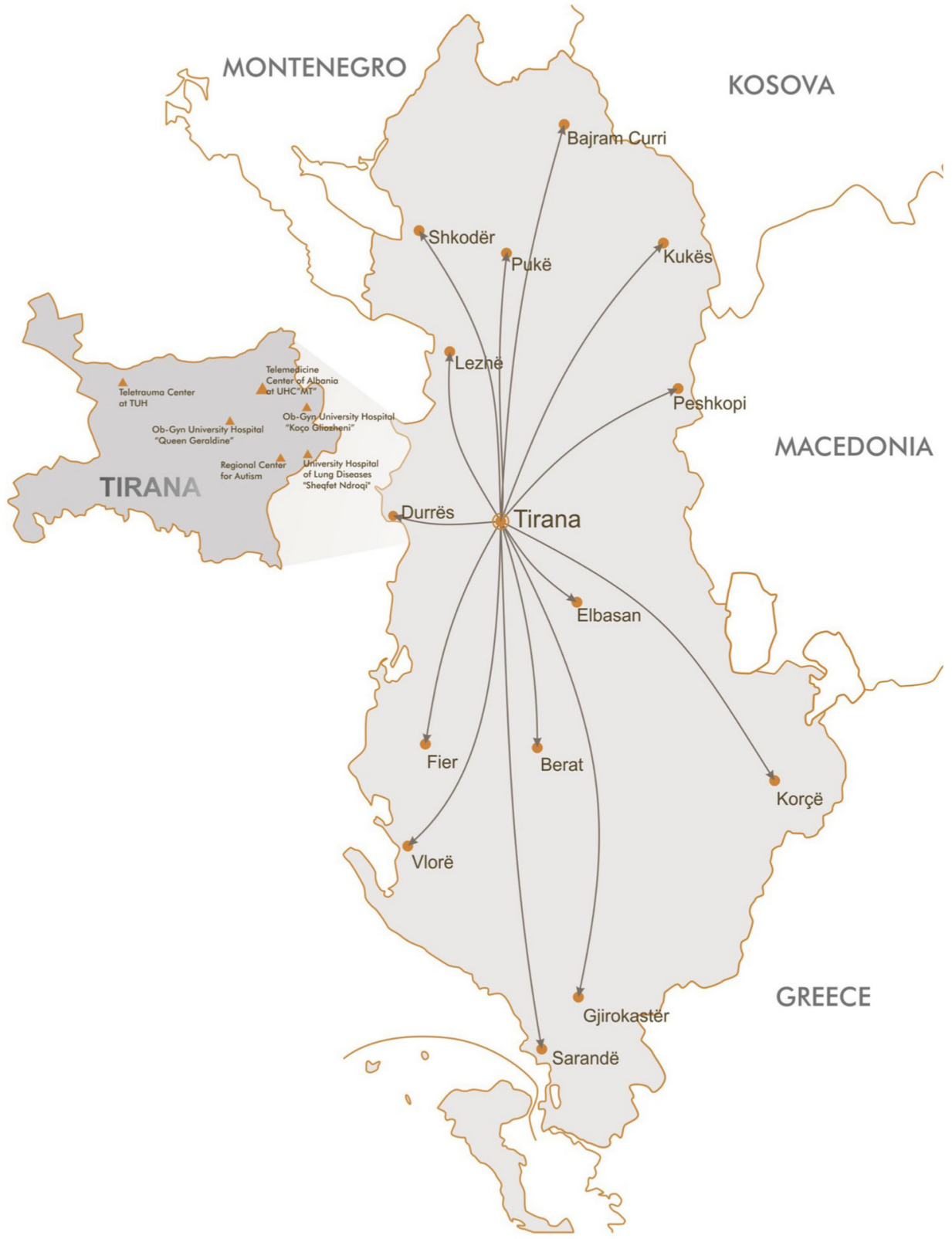

(reference 31)

Figure 1 Map of Albania telemedicine programme.

Foundation for International Education of Neurological Surgery pairs an LMIC healthcare training institution with an HIC institution. ${ }^{15}$ European and North American programmes have twinned with programmes in Africa, Central and South America, and Southeast Asia, among other regions. The Operation Giving Back programme of the American College of Surgeons has partnered 13 general surgery training programmes in the USA with Hawassa University in Ethiopia, sharing faculty and in-training personnel to improve the number and quality of general surgeons throughout sub-Saharan Africa. ${ }^{16} 17$ Twinning between HIC and LMIC training institutions increases efficiency and encourages global training standards. MCCs can serve as additional sites for HIC-LMIC twinning interaction, resulting in improved quantity and quality of healthcare personnel globally.

\section{INFORMATION TECHNOLOGY \\ Data collection and analysis}

Only when accurate data are available on (1) the patient's condition prior to care, (2) the care delivered, (3) the resources used and (4) the long-term outcomes can one begin continuous quality improvement. ${ }^{18}$ Large healthcare systems that have created sophisticated healthcare data collection and analysis programmes include the National Health Service in the UK and the Kaiser Healthcare System in the USA. The varying resources 

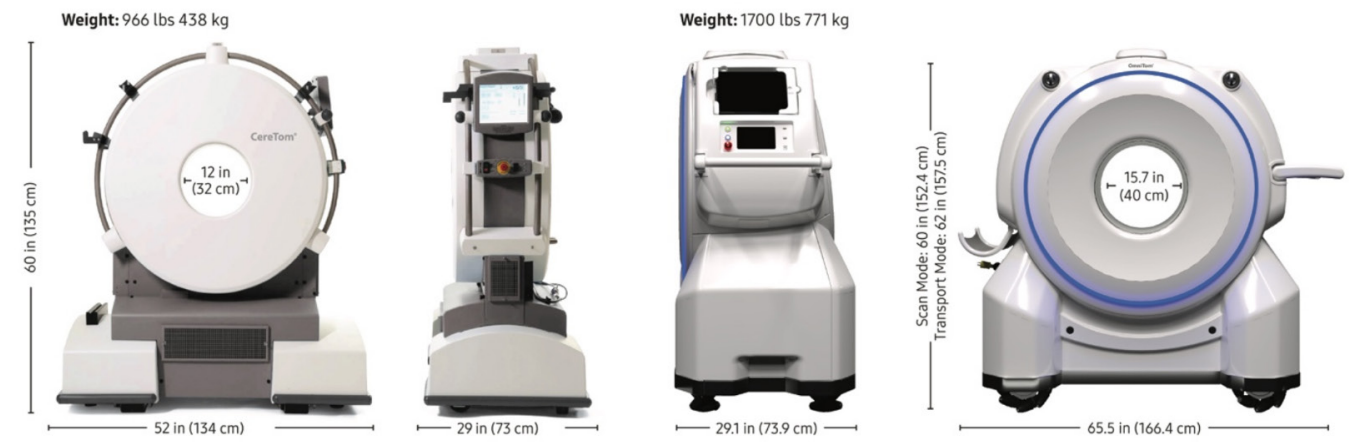

A. Left - Mobile head CT scanner (438 kg). Right - Mobile body CT scanner (726 kg). (reference 32)
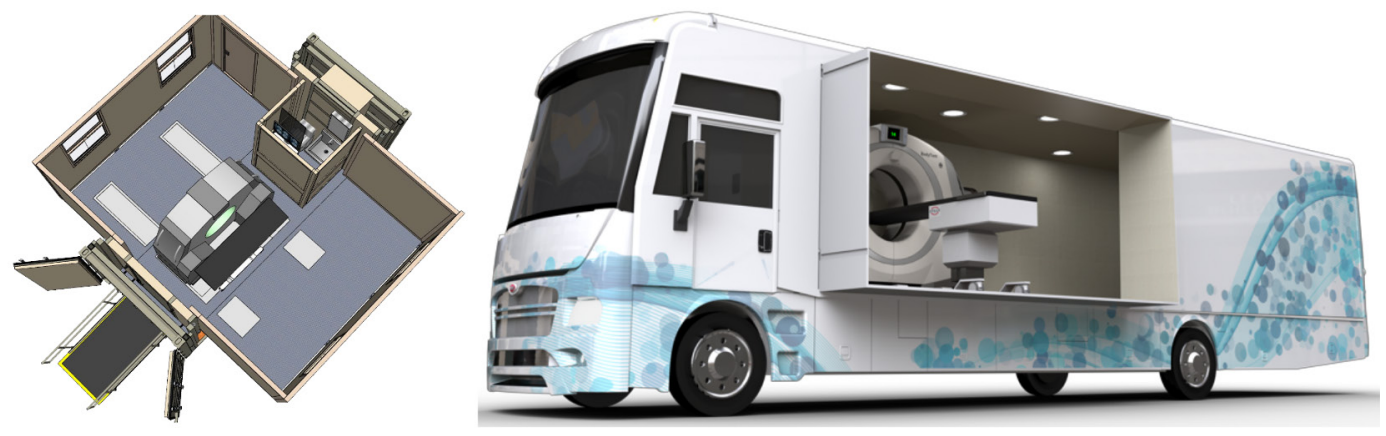

B. Left - Portable CT-equipped operating room. Right - Mobile CT-equipped clinic. (references 32 \& 33)

Figure 2 (A) Reconstruction-battery-equipped CT scanners. (B) Mobile CT-equipped facilities.

and needs at different MCCs around the world require a nimble and adaptable system-one where data collected at various MCCs can be compared. Diverse locations of MCCs permits cost-effective and quality-effective techniques arising at one MCC to be exported to other MCCs. Learning effective healthcare solutions from LMICs has been published by author NC. ${ }^{19} 20$

One example of comprehensive data collection and analysis is the electronic health ('e-health') system established at Westchester Medical Center, New York Medical College, near New York City, USA. ${ }^{21}$ By providing rich operational data (eg, through timestamps), data collected at every step of the patient's involvement in the healthcare system allow identification of bottlenecks, gaps and redundancies-and options for improvement of outcomes. Such data lead to conservation of limited healthcare resources, for example, identification of patients who can be safely treated in an intermediate rather than a critical care unit (CCU).$^{21} \mathrm{~A}$ recent commentary addresses the need for affordable critical care in LMICs. ${ }^{22}$

\section{Telemedicine}

Telemedicine benefits for healthcare include

- Extension of healthcare both geographically (through consultations to remote clinics) and temporally (through staffing during nights and other times of reduced specialist resources).

- Immediate dissemination of information during both disasters and routine care.
- Augmentation of resources (eg, experts as virtual surgical assistant for complex surgeries).

In disasters with a warning-such as hydrometeorological events (cyclones/hurricanes/typhoons and tsunamis) - a basic but resilient telemedicine system can be life-saving. One significant factor for the modest loss of life from Cyclone Phailin was the 31 telemedicine stations in the Indian state of Odisha: communication allowed the co-ordinated, timely evacuation of 1.3 million people to 600 storm shelters (table 1). ${ }^{23}$

State-of-the-art data collection and analysis goes handin-hand with telemedicine, including CCU settings. The value of tele-CCU programmes has been documented. $^{24} 25$ Another telemedicine application for enhancing 24/7/365 resource availability is teleultrasound. ${ }^{26}$ Ultrasound is an imaging modality more widely available in LMICs than more costly modalities, for example, CT and MRI. Teleintensivists can supervise healthcare personnel (including nurses) - who may have only modest ultrasound training-to perform basic ultrasound examinations. ${ }^{26}$

Telemedicine has been integrated into programmes for mass casualty disaster response: for example, since 2013, the North Atlantic Treaty Organization, under the Science for Peace and Security Programme, has been developing a Multinational Telemedicine System for disaster response. ${ }^{27}$

Country-wide telemedicine programmes have been developed by the founder of the International Virtual 

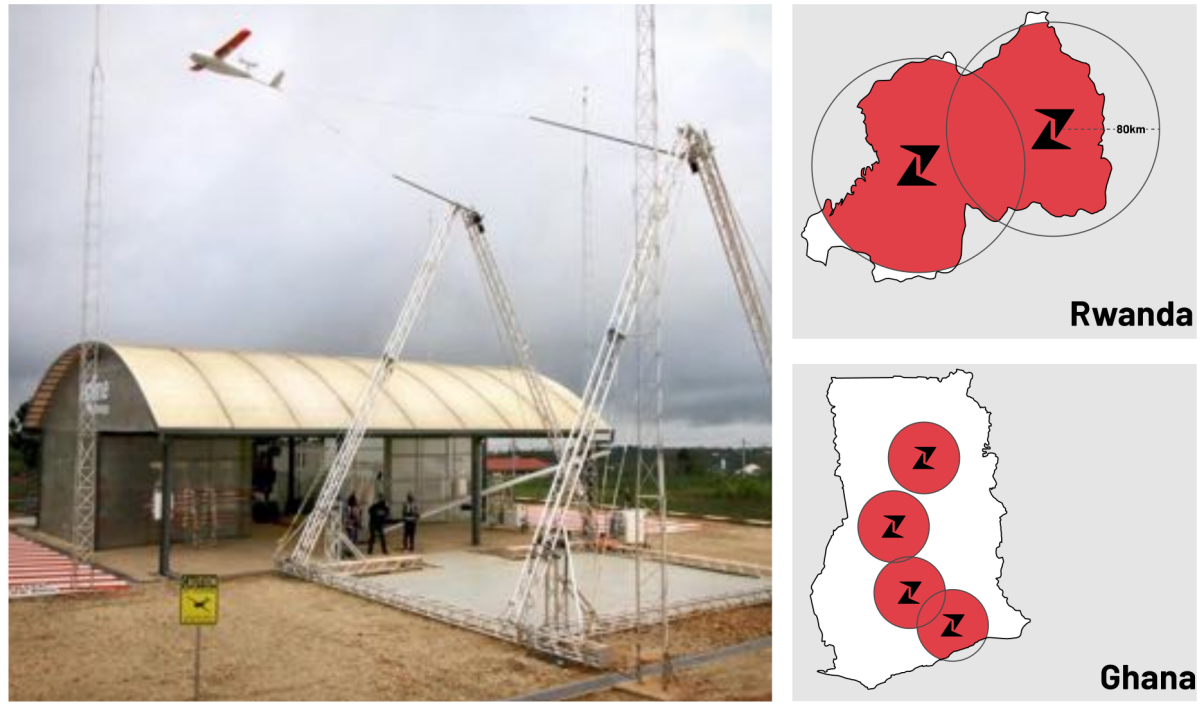

Left - drone launch centre in western Rwanda. Right - map of Zipline centres in Rwanda and Ghana. (reference 39)

Figure 3 Zipline drone delivery of medical resources in Africa.

e-Hospital (author RL). Both emergency and nonemergency care in Albania, Cabo Verde, Kosovo, the Philippines and Vietnam have benefited. A teleconsultation service to optimise neurotrauma care in Albaniawhere the only neurosurgical resources are in the capital, Tirana-has been implemented (figure 1). ${ }^{28}$ From 2014 to 2018, 590 patients had teleconsultations for neurotrauma-with a median response time of $20 \mathrm{~min}$. Two-thirds of the patients could be managed at the local centre, avoiding costly transfer of many patients by ambulance or helicopter to the National Trauma Centre in Tirana. ${ }^{28}$

\section{EQUIPMENT}

\section{Resilient mobile imaging and surgery}

Although 'resilient' is usually considered the ability to withstand catastrophic insults (such as earthquakes or storms), in many LMICs emergency care is frequently disrupted by events like electrical power outages. The association between power outages and a pregnant woman delivering in a healthcare institution versus at home was investigated for Maharashtra, India. ${ }^{4}$ With the average number of power outages-8.5 per month-the odds of delivering at home rather than in a healthcare facility increased $18 \%$; that is, each additional power outage resulted in $2 \%$ greater chance of a delivery at home. ${ }^{4}$

In LMICs, electrical power outages disrupt emergency surgery and critical care equipment (eg, ventilators) and likely also deter the populace from using those healthcare facilities:

We speculate... that power outages directly affect women's decisions to seek care: a woman may decide to stay at home if there is an outage but without any knowledge of how long the power outage may last. ${ }^{4}$
Battery-powered CT scanners-both head and body versions - can address both power outages at fixed facilities (hospitals) and mobile imaging needs at remote sites (figure 2) ${ }^{29}$ Mobile, self-sufficient, surgical field hospitals, equipped with such a battery-powered CT scanner, have also been developed (figure 2). ${ }^{29} 30 \mathrm{~A}$ ground ambulance can be retrofitted with a head CT scanner (cost US $\$ 175000$ ) for US $\$ 10000$ or less. Such mobile CT ambulances have enhanced trauma/stroke care in HICs-from Berlin to Cleveland.

The Lancet Commission on Global Surgery 2030 estimated that lost gross domestic product in LMICs due to injury and neoplasia will exceed US $\$ 1$ trillion per year by 2030, neoplasia costs exceeding injury. ${ }^{31}$ Body CT-equipped vehicles-mobile imaging clinics-have been developed for lung cancer screening (figure 2).$^{29}$ Imagine a mobile diagnostic vehicle (CT, ultrasound, laboratory) making daily trips to different regions of a country to perform dozens of diagnostic studies per day; those individuals with findings indicating additional evaluation or treatment (eg, MRI scan, surgery) could have timely follow-up at a (perhaps distant) tertiary facility.

\section{Robots and drones}

Robots and drones (unmanned aerial vehicles) for disaster response are being developed by academic institutions, commercial entities, governmental institutions and militaries worldwide. ${ }^{32}$ The Center for Robot-Assisted Search and Rescue, headed by Professor Robin Murphy at Texas A\&M University, has extensive experience with drones and robots for emergencies. 'Smart' drones-equipped with sophisticated sensors such as thermal imaging and laser-induced distance and ranging-can identify the living buried under rubble. Robots can improve both land and water rescue (eg, identification and retrieval of flood or building collapse victims). Combining such 


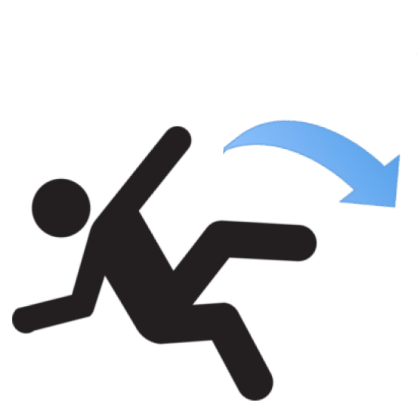

1. Fall or seizure detection, or emergency button press
2. Seizario gets location \& condition, then informs emergency contacts

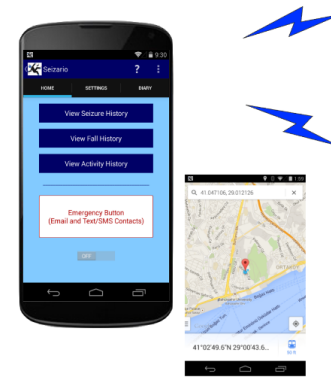

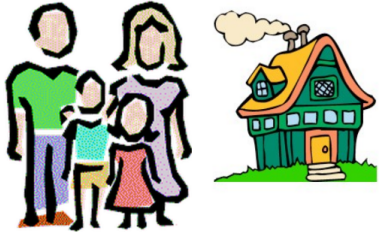

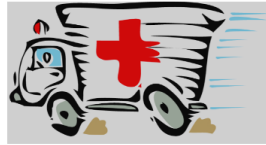

3. Family members, caregivers provide timely help

(reference 47)

Figure 4 Seizario smartphone app for immediate geographical localisation and emergency response notification.

drones and robots with a dispatcher wearing virtual reality goggles allows optimal triage of disaster response resources through constant updates of disaster scenes.

Drones can provide prompt delivery of medical resources, from vaccines and antibiotics to blood and laboratory tests to devices such as defibrillators. ${ }^{34}{ }^{35}$ Zipline uses battery-powered drones to deliver blood products, vaccines, and so on, across Rwanda and Ghana (figure 3). ${ }^{36}$ The benefit (time savings) of defibrillators transported by drone to a cardiac arrest victim has been documented. ${ }^{37-40}$

\section{IMPLEMENTATION}

\section{Prevention}

Community education programmes such as ThinkFirst and Pense Bem stress the negative consequences of risky behaviour. ThinkFirst, begun in the USA (1986) to educate school-age children, now has approximately 130 chapters across the USA and 40 international chapters from Algeria to Taiwan. ${ }^{41}$ Pense Bem ("Think Well")begun in Brazil (1995) and modelled after ThinkFirsthas been integrated into the Brazilian school system and now reaches approximately $20 \%$ of all school-age children in Brazil. ${ }^{42}$ In Peshawar, author TK began a community education injury prevention programme over 20 years ago; Peshawar's ThinkFirst programme received the ThinkFirst 2019 International Chapter of the Year Award.

Such injury prevention programmes-from risky behaviour of pre-teens to dangerous driving habits to domestic and other violence-are an integral part of the MCG project.

\section{Transport from injury scene to definitive care}

Methods used in HICs-ambulances with trained EMTs (and helicopters where feasible) - are integral to MCCs. Training follows the examples of the WHO EMT Initiative and AUSMAT. ${ }^{8}$ In Peshawar, a ground ambulance service with trained EMTs was begun in May 2017.
MCCs in LMICs can introduce novel techniques to improve prehospital care, two of which are presented below.

To decrease the high maternal mortality ratio of 583 per 100000 population in western Kenya, a mobile phone-based, 24/7 Uber-like transport system was developed to improve the number of antenatal and postnatal care visits and reduce the time to health facility for delivery. ${ }^{43}$ Personalised and interactive text messages and the transport system improved the odds of receiving at least four antenatal and four postnatal care visits fourfold to fivefold. Another benefit was enhanced community involvement: local transport vendors (largely Uber-like motorcycle operators) became aware of the benefit of prompt and continuing maternal and neonatal care.

Seizario is a smartphone app for persons with epilepsy (figure 4). ${ }^{44}$ The app immediately notifies others (family, healthcare personnel) that the patient is having a convulsive seizure (detected by the accelerometer) and provides the victim's location (through the global positioning system-GPS). Such an app can be expanded to detect persons involved in various injuries, from falls by the elderly to road traffic accidents to gun violence. Using the accelerometer and GPS smartphone capabilities, the location of the injured victim(s) can be immediately transmitted to emergency personnel. By having taxi, mini-bus and school-bus drivers, ambulance personnel and others have a smartphone with this app at all times when 'on the job' - and encouraging others at high risk to do so as well (the elderly, law enforcement personnel, those working in dangerous construction sites)-the time from injury to treatment can be markedly reduced, and thus outcomes significantly improved.

\section{Acute care}

Optimisation of acute care in LMIC settings is a topic worthy of book-length documentation. One aspect of MCCs is the integration of telemedicine into ongoing 


\section{Stakeholder Engagement Stakeholders Conference}

November 15-16, 2018 Islamabad, Pakistan

Sensitized key
stakeholders
(provincial,
government, private,
associations,
professional bodies,
children focus)

\begin{tabular}{|c|c|c|}
\hline $\begin{array}{l}\text { Promoted the need } \\
\text { for Situational } \\
\text { Analysis for } \\
\text { concrete data }\end{array}$ & $\begin{array}{l}\text { Decision to pass } \\
\text { Consensus } \\
\text { Statement and to } \\
\text { work on NVSC2025 } \\
\text { document }\end{array}$ & $\begin{array}{l}\text { - Formation of the } \\
\text { steering committee } \\
\text { to provide strategic } \\
\text { direction }\end{array}$ \\
\hline
\end{tabular}
children focus)

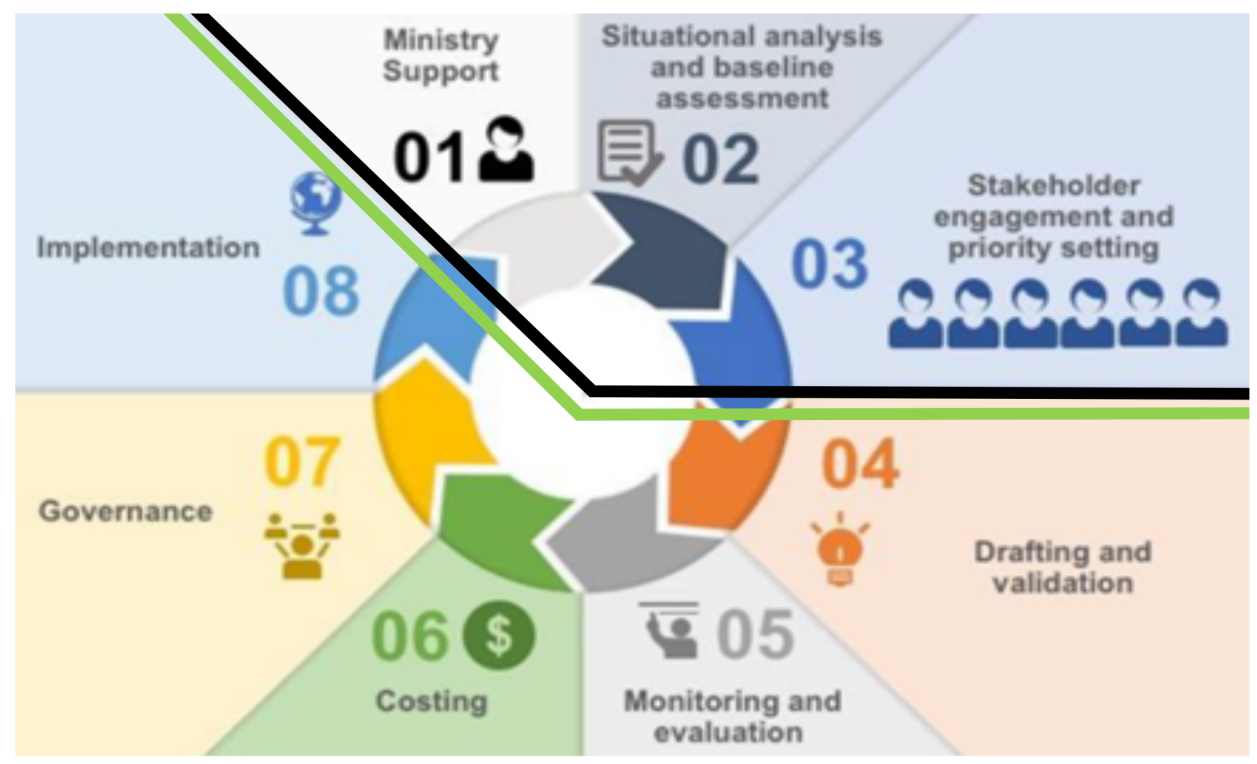

(courtesy of author HS)

Figure 5 Pakistan's national health vision 2025 programme.

24/7/365 care from CCU teleintensivists to remote clinics, as discussed above.

\section{Rehabilitation}

By developing minimum technical standards and recommendations for rehabilitation, WHO has acknowledged the importance of rehabilitation for disaster response. ${ }^{12}$ In Peshawar, rehabilitation has been an integral part of healthcare: cost-effective rehabilitation is a goal of the MCC project.

\section{PROGRESS}

\section{Progress: Iquique}

In Chile, communication with and support from the Chilean Ministry of Health for the MCC concept was established by author LQ. Author SA held an initial conference regarding an MCC in Iquique in 2018-bringing together the local health authorities, the Chilean military (Chilean Air Force Base in Iquique) and the Chilean Emergency Response Ministry (ONEMI). Follow-up meetings were arranged with (1) the Chilean Ministry of Health (April 2019) and (2) the Naval Hospital Director (October 2019).

\section{Progress: Peshawar}

Over the past decade in Peshawar, author TK has opened two hospitals, a medical school (100 students per year), a nursing school (50 students per year) and allied health professions programmes. Author TK thus has had longstanding interactions with local, provincial and national Pakistani health authorities. A community-based trauma prevention programme (now including ThinkFirst) has evolved over the past two decades. A ground ambulance service began in May 2017. The Pakistani Military Commander in Peshawar has expressed support for integration of civilian and military medical resources for the MCC in Peshawar in a series of meetings, most recently in November 2019. Several coauthors are facilitating MCC participation in Pakistan's National Health Vision 2025 programme, which includes a National Surgical, Obstetric and Anaesthesia Plan and a National Vision for Surgical Care (NVSC) (figure 5).

\section{CONCLUSION}

Recent publications on the need to expand surgical resources in LMICs to meet the UN SDGs for 2030 raise the question of implementation. ${ }^{31}{ }^{45-47}$ MCCs offer the benefits of trauma/stroke centres for both mass casualty response and ongoing day-to-day healthcare in the region 
served. MCCs incorporate innovations-technical and personnel-from both LMICs and HICs. From smartphones to telemedicine, MCCs in LMICs take advantage of new technologies, potentially without the burden of legacy healthcare infrastructure. Standardisation of advanced data collection and analysis across MCCs-both clinical and research-produces the 'big data' necessary for evidence-based global healthcare. Twinning MCCs in LMICs with medical centres in HICs creates two-way interactions in patient care, research and healthcare education. Over time, this permits standardisation of treatment, training and licensure across national boundaries.

In summary, MCCs address the goals set by the WHO Director-General for emergency and trauma care as well as the criteria of the checklist for implementation of the Sendai Framework for Disaster Risk Reduction.

With only a decade remaining to reach the 2030 SDGs, feasible and concrete programmes are needed to advance global healthcare. MCCs are a practical way to achieve the healthcare-related SDGs for 2030.

\section{Author affiliations}

${ }^{1}$ Neurosurgery, Almirante Nef Naval Hospital \& Valparaíso University, Viña del Mar, Valparaíso, Chile

${ }^{2}$ Neurosurgery, Valparaiso University School of Medicine, Valparaiso, Chile

${ }^{3}$ World Federation of Neurosurgical Societies, Nyon, Switzerland

${ }^{4}$ Neurosurgery, Northwest General Hospital and Research Centre, Peshawar,

Pakistan

${ }^{5}$ Neurosurgery, Northwestern University Feinberg School of Medicine, Chicago, Illinois, USA

${ }^{6}$ Program in Global Surgery and Social Change, Harvard Medical School Department of Global Health and Social Medicine, Boston, Massachusetts, USA

${ }^{7}$ University of Miami School of Medicine, Miami, Florida, USA

${ }^{8}$ Surgery, New York Medical College, Valhalla, New York, USA

${ }^{9}$ International Virtual eHospital Foundation, Hope, Idaho, USA

${ }^{10}$ School of Public Health and Administration, Universidad Peruana Cayetano Heredia, Lima, Peru

${ }^{11}$ Neurosurgery, University of Wisconsin-Madison School of Medicine and Public Health, Madison, Wisconsin, USA

${ }^{12}$ Chair, Foundation for International Education in Neurological Surgery, Madison, Wisconsin, USA

${ }^{13}$ Neurosurgery, Alfred Hospital, Melbourne, Victoria, Australia

${ }^{14}$ Royal Australian Army Medical Corps, Melbourne, Victoria, Australia

${ }^{15}$ Anesthesiology, Internal Medicine, eHealth, Westchester Medical Center, Valhalla, New York, USA

${ }^{16}$ House of Lords Parliamentary Group on Global Health, London, UK

${ }^{17}$ Nursing Now, London, UK

${ }^{18}$ Director, Centre for Essential Surgical Network, Indus Health Network, Karachi, Sindh, Pakistan

${ }^{19}$ Center for Global Health Delivery, Harvard Medical School, Dubai, United Arab Emirates

${ }^{20}$ Assistant Professor \& HSC Health and Social Justice Scholar, University of Louisville School of Nursing, Louisville, Kentucky, USA

${ }^{21}$ Neurosurgery, Azienda Ospedaliera Universitaria Senese, Siena, Toscana, Italy

${ }^{22}$ Neurosurgery, Aga Khan University, Karachi, Sindh, Pakistan

${ }^{23}$ Health Services, Government of Pakistan, Islamabad, Islamabad, Pakistan

${ }^{24}$ Nanotechnology and Smart Systems, NASA Ames Research Center, Moffett Field, California, USA

Twitter Haitham Shoman @haitham shoman

Contributors All authors contributed to project/concept development, literature search, writing. RJA, LQ and HS contributed to tables and figures.
Funding The authors have not declared a specific grant for this research from any funding agency in the public, commercial or not-for-profit sectors.

Competing interests None declared.

Patient consent for publication Not required.

Provenance and peer review Not commissioned; externally peer reviewed.

Data availability statement There are no data in this work.

Open access This is an open access article distributed in accordance with the Creative Commons Attribution Non Commercial (CC BY-NC 4.0) license, which permits others to distribute, remix, adapt, build upon this work non-commercially, and license their derivative works on different terms, provided the original work is properly cited, appropriate credit is given, any changes made indicated, and the use is non-commercial. See: http://creativecommons.org/licenses/by-nc/4.0/.

\section{ORCID iDs}

Haitham Shoman http://orcid.org/0000-0003-3408-7020

Russell J Andrews http://orcid.org/0000-0003-1771-1768

\section{REFERENCES}

1 World Health Organization (WHO). Health in 2015: from MDGs, Millennium Development Goals to SDGs, Sustainable Development Goals. Geneva: WHO, 2015: pp216.

2 Thind A, Hsia R, Mabweijano J, et al. Prehospital and emergency care. In: Disease control priorities (3rd ed): vol 1, essential surgery. In: Debas HT, Donkor P, Gawande A, et al, eds. Washington DC: World Bank, 2015.

3 WHO Director-General. Emergency and trauma care. Emergency care systems for universal health coverage: ensuring timely care for the acutely ill and injured report A72/31. Geneva: WHO, 2019: 6.

4 Koroglu M, Irwin BR, Grépin KA. Effect of power outages on the use of maternal health services: evidence from Maharashtra, India. BMJ Glob Health 2019;4.

5 UN Office for Disaster Risk Reduction. Concise guide: strategic approach to capacity development for implementation of the Sendai framework for disaster risk reduction-a vision of risk-informed sustainable development by 2030. Geneva: UNDRR, 2019: 156.

6 Crisp N, Brownie S, Refsum C. Nursing and midwifery: the key to the rapid and cost-effective expansion of high-quality universal health coverage. Doha, Qatar: World Innovation Summit for Health, 2018: 42.

7 Niinistö S, Sirisena M, Vázquez T, et al. Time to deliver: report of the WHO independent high-level commission on noncommunicable diseases. Geneva: WHO, 2018: 44.

8 Australian medical assistance teams and national critical care and trauma response centre. Available: https://www. nationaltraumacentre.nt.gov.au/ [Accessed 15 Dec 2018].

9 World Health Organization emergency medical teams website, 2019. Available: https://www.who.int/hac/techguidance/preparedness/ emergency_medical_teams/en/ [Accessed 15 Dec 2018].

10 World Health Organization emergency medical teams strategic advisory group meeting no; 2018.

11 Office of the Assistant Secretary for Preparedness and Response. Disaster Medical Assistance Teams. US Department of Health and Human Services, 2017. Available: https://www.phe.gov/ Preparedness/responders/ndms/ndms-teams/Pages/dmat.aspx [Accessed 27 Apr 2019].

12 World Health Organization Emergency Medical Teams. Emergency medical teams: minimum technical standards and recommendations for rehabilitation. Geneva: World Health Organization, 2016: 54.

13 Haglund MM, Kiryabwire J, Parker S, et al. Surgical capacity building in Uganda through twinning, technology, and training camps. World J Surg 2011;35:1175-82.

14 Romach MK, Rutka JT. Building healthcare capacity in pediatric neurosurgery and psychiatry in a post-Soviet system: Ukraine. World Neurosurg 2018;111:166-74.

15 Dempsey RJ. Editorial. Global neurosurgery: the role of the individual neurosurgeon, the Foundation for International Education in Neurological Surgery, and "service through education" to address worldwide need. Neurosurg Focus 2018:45:E19.

16 Boeck MA, Goodman LF, Lin Y, et al. American College of Surgeons member involvement in global surgery: results from the 2015 Operation Giving Back Survey. World J Surg 2018;42:2018-27.

17 Ferrada P, Sakran JV, Dubose J, et al. Above and beyond: a primer for young surgeons interested in global surgery. Bull Am Coll Surg 2017; 102:33-8. 
18 Kruk ME, Gage AD, Joseph NT, et al. Mortality due to lowquality health systems in the universal health coverage era: a systematic analysis of amenable deaths in 137 countries. Lancet 2018:392:2203-12.

19 Crisp N. Turning the world upside down: the search for global health in the 21st century. Boca Raton FL: CRC Press, 2010: 240.

20 Crisp N. One world health: an overview of global health. Boca Raton FL: CRC Press, 2016: 334.

21 Becker CD, Bowers C, Chandy D, et al. Low risk monitoring in neurocritical care. Front Neurol 2018;9.

22 Turner HC, Hao NV, Yacoub S, et al. Achieving affordable critical care in low-income and middle-income countries. BMJ Glob Health 2019;4:e001675.

23 Andrews RJ, Quintana LM. Unpredictable, unpreventable and impersonal medicine: global disaster response in the 21st century. EPMA Journal 2015;6:e1-12.

24 Lilly CM, McLaughlin JM, Zhao H, et al. A multicenter study of ICU telemedicine reengineering of adult critical care. Chest 2014;145:500-7.

25 Fusaro MV, Becker C, Scurlock C. Evaluating tele-ICU implementation based on observed and predicted ICH mortality: a systematic review and meta-analysis. Crit Care Med 2019;47:501-7.

26 Becker C, Fusaro M, Patel D, et al. The utility of teleultrasound to guide acute patient management. Cardiol Rev 2017;25:97-101.

27 Doarn CR, Latifi R, Poropatich RK, et al. Development and validation of telemedicine for disaster response: the North Atlantic Treaty Organization multinational system. Telemed e-Health 2017;24:1-12.

28 Olldashi F, Latifi R, Parsikia A, et al. Telemedicine for neurotrauma prevents unnecessary transfers: an update from a nationwide program in Albania and analysis of 590 patients. World Neurosurg 2019;128:e340-6.

29 Product information, NeuroLogica/Samsung. Available: https:// neurologica.com [Accessed 27 Apr 2019].

30 Product information, Forts Medical. Available: https://fortsmedical. com [Accessed 27 Apr 2019].

31 Meara JG, Leather AJM, Hagander L, et al. Global surgery 2030: evidence and solutions for achieving health, welfare, and economic development. Lancet 2015;386:569-624.

32 Handford C, Reeves F, Parker P. Prospective use of unmanned aeria vehicles for military medical evacuation in future conflicts. J R Army Med Corps 2018;164:293-6.

33 Murphy RR. Disaster robotics. Cambridge MA: MIT Press, 2014: 240.

34 Bhatt K, Pourmand A, Sikka N. Targeted applications of unmanned aerial vehicles (drones) in telemedicine. Telemed J E Health 2018;24:833-8.

35 Balasingam M. Drones in medicine-the rise of the machines. Int $J$ Clin Pract 2017;71:e12989.
36 Product information, Zipline. Available: https://flyzipline.com [Accessed 27 Apr 2019].

37 Claesson A, Fredman D, Svensson L, et al. Unmanned aerial vehicles (drones) in out-of-hospital-cardiac-arrest. Scand J Trauma Resusc Emerg Med 2016;24.

38 Claesson A, Bäckman A, Ringh M, et al. Time to delivery of an automated external defibrillator using a drone for simulated outof-hospital cardiac arrests vs emergency medical services. JAMA 2017;317:2332-4.

39 Boutilier JJ, Brooks SC, Janmohamed A, et al. Optimizing a drone network to deliver automated external defibrillators. Circulation 2017;135:2454-65

40 Van de Voorde P, Gautama S, Momont A, et al. The drone ambulance [A-UAS]: golden bullet or just a blank? Resuscitation 2017;116:46-8

41 Think First National Injury Prevention Foundation. Available: https:// thinkfirst.org [Accessed 27 Apr 2019].

42 Salvarani CP. Prevention of traumatic brain injury in Brazil-the Pense Bem ("Think Well") program of the Brazilian Society of Neurosurgery. World Federation of Neurosurgical Societies Newsletter 2018

43 Onono MA, Wahome S, Wekesa $\mathrm{P}$, et al. Effects of an expanded Uber-like transport system on access to and use of maternal and newborn health services: findings of a prospective cohort study in Homa Bay, Kenya. BMJ Glob Health 2019;4:e001254.

44 Seizario: detecting seizures and falls. Available: https://seizario. healthhappy.com [Accessed 27 Apr 2019].

45 Alkire BC, Shrime MG, Dare AJ, et al. Global economic consequences of selected surgical diseases: a modelling study. Lancet Glob Health 2015;3 Suppl 2:S21-7.

46 Shrime MG, Dare AJ, Alkire BC, et al. Catastrophic expenditure to pay for surgery worldwide: a modelling study. Lancet Glob Health 2015;3 Suppl 2:S38-44.

47 Dare AJ, Ng-Kamstra JS, Patra J, et al. Deaths from acute abdominal conditions and geographical access to surgical care in India: a nationally representative spatial analysis. Lancet Glob Health 2015;3:e646-53

48 International Federation of Red Cross and Red Crescent Societies. Myanmar: cyclone Nargis 2008 facts and figures. Available: http:// www.ifrc.org [Accessed 30 Mar 2014].

49 Government of India, India Meteorological Department. Cyclonic Storm PHAILIN over the Bay of Bengal: a report. Available: http:// www.imd. gov.in/section/nhac/dynamic/ phailin [Accessed 30 Mar 2014].

50 Republic of the Philippines, National Disaster Risk Reduction and Management Council. Effects of Typhoon Yolanda (Haiyan) [NDRRMC Update SitRep No. 107, 14 March 2014]. Available: http:// www.ndrrmc.gov.ph [Accessed 30 Mar 2014]. 